\title{
Brain Drain: Migration of Healthcare Professionals in a Globalized World
}

\author{
${ }^{1}$ Gaurav Mahindra, ${ }^{2}$ Hamendra Kumar Dangi
}

\begin{abstract}
Social, economic and technological developments due to globalization have led to a surge in international demand for skilled workforce. Developed economies have made concerted efforts in not only attracting but also in retaining such human capital. Healthcare sector has been no exception. With limited career opportunities within their own country and a host of pull factors in developed countries, India and other developing countries have seen an exodus of medical and other professionals, what is known as 'Brain Drain'. Shortages thus resulting from migration of health workers have even mitigated the effects of increased domestic healthcare spending. The health workers hold strategic importance in a nation's health systems and disease control initiatives. The resulting imbalances could have a detrimental effect on the social as well as economic fabric of such sending countries. This study is an effort in understanding the factors encouraging human capital flight and thus seeking short-term and long-term measures in dealing with it. This research brings forth strategies to deal with brain drain by forming mutually beneficial relationships with the diasporas. This reciprocity will lead to circulation of skills between source and receiving countries. Formulating suitable policies would ensure correcting the human resource imbalances within countries on a sustainable basis.
\end{abstract}

Keywords: Brain drain, Human capital flight, Migration of health workers.

How to cite this article: Mahindra G, Dangi HK. Brain Drain: Migration of Healthcare Professionals in a Globalized World. Int J Res Foundation Hosp Healthc Adm 2014;2(2):63-72.

Source of support: Nil

Conflict of interest: None

\section{INTRODUCTION}

The term 'Brain Drain' indicates the movement of skilled human workforce across geographies, essentially from the developing to the developed nations. These educated individuals envisage a more prosperous and brighter future for themselves by doing so. This topic has been a source of great debate and will continue to be due to its economic and social repercussions in particular. Most of the discussions

\footnotetext{
${ }^{1}$ MBA Student, ${ }^{2}$ Assistant Professor

${ }^{1,2}$ Faculty of Management Studies, University of Delhi, New Delhi, India
}

Corresponding Author: Gaurav Mahindra, MBA Student Faculty of Management Studies, University of Delhi, New Delhi-110007, India, e-mail: mahindra.gaurav@gmail.com get focussed around its economic aspects but the impact of can be felt much beyond this aspect only.

It follows the overall trajectories and flow of human resources between geographies. It carries with it social as well as political implications for the source countries in particular. The irony here being many of the human resources developing countries lose to the wealthy countries are the exact people they can ill afford to, the highly skilled and educated ones.

Skilled human resources are increasingly been seen as the most valuable asset any society can possess. Any amount of technology innovation and advancement cannot replace human capital. Therefore considering its importance, brain drain or emigration of skilled professionals becomes an emotive issue in developing nations like India and China which need innovative ways to optimize their resources. Healthcare is a relevant concern here as it witnesses the greatest impact due to migration of doctors and medical professionals. Controlling the spread of various diseases is both a capital and manpower intensive activity. Such countries are already facing a huge socioeconomic burden of disease control. Ironically, they also experience the greatest exodus of educated and skilled healthcare professionals.

Over the years measures to control and benefit from such migration have been suggested by various authorities and policy makers. As the phenomenon of globalization spreads even more brain drain has gained more importance among various nations directly impacted. However, long-term measures to minimize its impact on vulnerable nations has remained an elusive and challenging endeavor. India and other developing countries can learn from in each other in strategising policies to attract and retain skilled human resources.

Scarce funding as well as insufficient technical and material resources to carry out research back home are among the major determinants in developing countries which lead to emigration of professionals (Popescu, Patrasca and Chivu 2006).

Despite all previous efforts, no universally accepted method has been established to tackle this issue. Source countries continue to be in a quandary regarding the merits and demerits of brain drain. Developed countries which receive such individuals are facing a shortage of skilled manpower and are therefore in favor of this phenomenon. 
Their demand supply mismatch is a huge incentive for professionals to migrate abroad. The rationale or criteria that should be followed by policy makers and authorities' remains an area of concern for various healthcare managers and government agencies.

Changing demographics in countries is an important indicator of the future trend. Young and aspiring doctors look for a better future and wish to capitalize on their skills. This study was conducted among students of medical and dental streams to find out their individual reasons to migrate abroad.

The study conducted was instrumental in determining various factors having a significant impact on brain drain. A combination of socioeconomic factors along with opportunities for career development and education, international exposure and dynamics involving market forces were the key constituents in student decision making. These results provide a perspective on the various external and internal factors individuals consider before deciding on their future.

Like all events even brain drain has its positive and negative implications. A correct balance between the two is to be achieved. Therefore authorities must design a mechanism which can capitalize on the skills, knowledge and expertise acquired by the diaspora along with the huge flow of remittances which comes back to the source country. Simultaneously, initiate a process to strengthen domestic infrastructure and capabilities to attract talent and retain it.

Policy makers and authorities that are involved with human resources could consider these factors in their decision making in order to maximize domestic human capital. Therefore it is for each source country to make the most out of this, prepare and implement policies which deal with it effectively and urgently. Finding solutions to these demanding issues could pave the way in better utilization of the migrant knowledge, skills and innovative capabilities by the source country.

The remainder of the paper is structured as follows. The next section describes past data and literature pertaining to brain drain that has been reviewed. Followed by, the hypotheses assumed for the study. The aims and objectives of carrying out this study form the next section. An overview of the methodology including data source, sampling frame and empirical model undertaken in this study has been discussed in the following section. Subsequent section includes the analysis of the data using proposed model. Lastly, conclusion along with scope for further research is discussed.

\section{Literature Review}

The term 'Brain Drain' is the net flow of human capital expertize heavily in one direction (Salt 1997). The word 'Brain' explains any attribute, skill or competency that is a potential asset. Whereas the word 'Drain' indicates this rate of exit, beyond the desired level leading to a shortage of talent. The overall implication is the exodus of the most talented at an appreciable, sometimes alarming rate (Bushnell and Choy 2001).

As early as in 1981, the dictionary of modern economics deciphered brain drain as: 'The migration of educated and skilled labor from poorer to richer countries.' Acquiring education is usually cheaper in poorer, labor surplus countries owing to government subsidy. These skills provide enhanced financial returns on moving to developed economies which often frame legislations to suit their own needs.

Human resources are a vital force in any nation's capacity building and capability enhancement. At the end of the day, every new technological innovation is due to human intervention. In addition, capable human expertize is also needed to ensure optimum utilization of technology. Therefore, scarcity of resources arising out of brain drain is of concern to all countries and more so to the developing countries. Also, education in developing countries is largely financed by public resources. Therefore, the damages are largely created in the source countries due to a misbalance between personal and public/social advantages (Bhagwati and Hamada, 1974).

Many wealthy countries follow selective immigration policies when it comes to human capital. As a result human capital tends to flow where it is plenty already (Easterly and Levine, 2001).

Although this problem saw its emergence as early as in the 1940's when European professionals emigrated to the UK and US, it was made an international agenda in 1973, when the UN Secretary General was requested to prepare a report on how to deal with this issue (Grubel and Scott 1977).

According to the United Nations (2002), the period between 1990 and 2000 saw international migrant number surge from 154 to 175 million.

In the 1990's, the phenomenon of brain drain saw a shift in focus from the 'pushing/supply factors' from developing countries to the 'pulling/demand factors' from the developed countries. Recent trends suggest that the competition for skilled professionals is only going to grow in the coming years.

Enhanced opportunities for professional development, international experience and financial rewards significantly impact an individual's decision to migrate. The lack of relations between professionals of a nation working and settled abroad with their home universities does not help the situation. This leads to low levels of interest among the migrated population to return to their home countries (Popescu, Patrasca and Chivu, 2006).

Many poor countries encounter an extra ordinarily high proportion of skilled nationals residing in rich countries. 
Many of the developed countries have exceptionally high levels of skilled immigrants as compared to non-skilled immigrants.

The United States has been the main focal point for foreign skilled workers with nearly $40 \%$ of its foreign-born adult population having tertiary level education. Since the early 1990s, under the H1B temporary visa plan nearly 9,00,000 highly skilled professionals, essentially IT workers, from India, China, Russia and OECD countries (Canada, UK, Germany) have shifted base to the United States. Figures suggest nearly $32 \%$ of all foreign students studying in the OECD countries end up for work in US.

In 1999 as much as $25 \%$ of all H1B visa holders were previously students enrolled at US universities (Source: OECD observer).

These movements have been also been a result of selective dismantling of rich country barriers to immigration of the highly skilled from poor countries (Kapoor and McHale 2005). This trend is primarily due to gaining competitive advantage in emerging knowledge based industries, aging of rich country populations or due to broader globalization and trade by attracting the highly educated individuals.

Currently, those applying for the H1B visa are entitled to have the dual intent of attaining temporary work status but intending for permanent residency as well (Kapur and McHale 2005).

Between 2000 and 2003, the US congress increased the annual cap on temporary work visas for skilled professionals under its H1B visa program, from 115,000 to 195,000 (Source: OECD observer).

This increased competition for developing country talent affects their developmental prospects. Most importantly it might affect a source country's capability to build domestic institutions, infrastructure and long-term educational machinery. Medical professionals at many developing countries are unable to use advanced technology and infrastructure due to lack of access and availability which is not the case in developed nations (Hamilton and Yau 2004).

The irony of poor quality is infrastructure builders are most likely to leave where institutional setup is needed the most (Kapur and Mchale 2005). The disadvantages of emigration from a sender country can be equated to the advantages of immigration in a receiving country but with an opposite sign.

One of India's most prestigious establishments, the All India Institute of Medical Sciences witnessed 56 and 49\% migration rate for graduate doctors between 1956 to 80 and 1990 to 1999 respectively (Desia, Kapur, McHale \& Rogers 2009). A novel way of monetising the expatriates abroad was suggested by Professor Bhagwati in 1970's, termed as 'Bhagwati Tax'. This was intended to be levied on all citizens abroad, similar to the way the Americans living outside their country are. Therefore, various control and compensation mechanisms become relevant in order to utilize its benefits and mitigate the challenges and reduce the negative impact.

On the other hand, there are arguments which are in favor of skilled professionals settling abroad. This viewpoint takes into consideration the human rights perspective. Since, a nation cannot impose sanctions on citizens from settling abroad, it should be able to nurture their loyalty instead. The diaspora should be integrated through more rights and incentives.

Important correlation was observed between (a) the strength of the relationship with one's former university/ colleagues and (b) one's preference to come back and work in their home country (Popescu, Patrasca and Chivu 2006).

This would encourage inflow of skills, knowledge, expertise and remittances back into source country. Effective utilization of these precious resources in program implementation would ensure some respite from brain drain if not all. Optimum use of technology and manpower would enable improvement in domestic institutions, paving a way for the diaspora to even return back. Therefore, creating domestic innovation and knowledge centres along with connecting and networking with diaspora leads to improvement in a nations infrastructure. These measures provide a roadmap for benefitting from the existing situation.

The repatriation measures should be gradual and selective. The process of bringing back diasporas should focus first and foremost on the best scientists and doctors in the priority areas in order to fill the gaps. This must begin with a better understanding of their expectations and providing enough incentives to fulfil their requirements.

Even the developed countries are formalizing strategies to bring back their own skilled professionals from other nations. In 2000, the Wolfson foundation, a research charity, along with the British government launched a controversial 5 -years research award. It was a $£ 20$ million scheme which intended to bring back quality British expatriate scientists home (Source: OECD observer).

The time spent abroad after completion of studies is of considerable importance in deciding to stay abroad or not. It was observed, the more time spent abroad, the higher the chances of staying back (Popescu, Patrasca and Chivu 2006).

The future reintegration process should focus on the sociocultural aspect as well. Many professionals leave a country for various reasons. Therefore, their needs and aspirations need considerable attention before laying the foundation of their resettlement. 


\section{Hypothesis}

Currently, wage differentials between developing and developed countries are large. A small increase in healthcare wages in source countries will not influence the supply of healthcare migrants significantly. Thus, the financial changes will have little impact. The requirement is to review the exodus from a social, political, and economic framework. Local security development needs to be emphasized. Hence, the following question gains significance, as to how socioeconomic conditions influence human mindset? Therefore, the following hypothesis was formulated to answer the research question.

$H_{1}$ : Improving domestic socioeconomic conditions balances brain drain.

Next consideration was about improving and increasing educational standards. Mobility of skilled professionals is a reality of the 21st century which we all need to accept. All countries irrespective of their standing in the world are competing with the best institutions for high quality manpower. It is wiser to accept and work positively to deal with this reality. Possible explanation could be the environment. Favorable and appropriate political decisions, infrastructure, technical know how, funding and scientific community are a few essential for science and technology to prosper. Developing countries generally lack these essentials. These expatriates can give immense contributions back home in their native countries. This could be done by developing joint research projects, training programs and teaching associations. The result could be far more effective flow of knowledge and information. Emigration of talented individuals provides a positive feedback motivating students to look forward to high quality education. This raises prospects for growth itself by improving human capital. This has lead to the formulation of second hypothesis.

$\mathrm{H}_{2}$ : Enhancing educational infrastructure positively influences professional migration.

The importance of an international experience was considered next. Work experience in different societies and countries provides a rich experience along with the monetary gains accompanying it. It would be immature to create new obstacles to the movement of people between countries. Sharing of knowledge and expertise by professionals working overseas can be made possible by partnering their institutions in innovative programs. Flexible training schemes allowing overseas doctors to work in developing countries should be encouraged. Long-term partnerships, with the help of clinical and teaching infrastructure of institutions in developing countries could result in better research. Overseas doctor training schemes can be evaluated through an audit with regards to their utility and outcome. Therefore, the possibility of involving well established foreign institutions in sharing their expertise arises. Hence, considering this point the following hypothesis was formulated.

$\mathrm{H}_{3}$ : Collaborating with Foreign universities improves educational experience.

Finally, remuneration parity between healthcare professionals with professionals in other sectors in the economy is crucial. India is an emerging economy which is driving prices higher each fiscal due to mismatched demand supply of resources. Also healthcare is one sector which is seen as a social service rather than any business opportunity. However, the fact remains inflation affects us all equally. Compounding this problem is the fact professional's in IT, services and manufacturing blue collar personnel show carrier advancement much faster than healthcare personnel. Therefore, medical and paramedical staff look for greener pastures abroad. Demographic realities in the developed economies are ensuring an ever increasing demand for healthcare. The present mismatch in the demand/supply relation among doctors abroad leads to increased exodus. Comparative salaries abroad are way more substantial and fuels better fulfilment of aspirations among the youngsters. Therefore ways and means to allow market to determine its own course needs to be considered. Hence, a hypothesis related to the market forces was made.

$\mathrm{H}_{4}$ : Bringing parity between healthcare and other industry sectors positively influences brain drain.

\section{Objectives}

The main objective of the study was to understand the influence of specific factors on the phenomenon of brain drain in the context of a developing country, such as India. Specifically the following objectives were framed:

- To determine the factors causing human capital flight.

- To understand the benefits and drawbacks of brain drain with respect to the source country.

- To identify intrinsic areas of improvement within a source country in order to control brain drain.

- To devise a mechanism for converting brain drain into wisdom gain.

\section{METHODOLOGY}

A structured questionnaire was used to conduct a survey in order to determine important factors considered by students in their decision making. The various responses were measured on the universally accepted Likert scale. The proposed model consisting of these potential factors was assessed using a structure equation model (SEM). The significance of statistics ensured a valid and reliable model leading to acceptance of various hypotheses which were assumed. 


\section{Research Design and Data Collection}

The present study was a prospective, cohort study. A detailed review of the existing literature guided us in short listing certain key factors which influence brain drain. A model linking key factors for migration was hypothesized. A structured questionnaire was designed which was pilot tested at Maulana Azad Institute of Dental Sciences, Delhi. After considering the responses and difficulty levels suitable changes in the questionnaire were made. Subsequently, a survey data collection was carried out among undergraduate final year students from Medicine and Dental Streams at University College of Medical Sciences and Maulana Azad Institute of Dental Sciences, Delhi between 1st Jan, 2014 and 15th Feb, 2014.

\section{MODEL LINKING VARIOUS FACTORS AFFECTING BRAIN DRAIN}

Brain drain is a phenomenon which is influenced by number factors which could be either personal or societal in nature. Although it affects all the countries, its magnitude and impact is greatest with respect to developing countries. Developed/ industrialized nations continue to exert a pull force which enables enough incentives for skilled professionals to leave developing nations and fulfil their aspirations. Therefore a close examination reveals multiple reasons for the exodus. In this research, the most valid factors are chosen for empirical validation which could hold true for most developing nations.

The model proposed in this paper will be validated through SEM which is presented in Figure 1.

\section{ANALYSIS}

Proposed relationships among identified performance measurement model have been validated using parameter estimation and goodness-of-fit statistics of structural equation modeling (using AMOS 18.0). On the basis of results obtained, a model to link underlying factors and performance of relief logistics has been proposed.

\section{Definition of Constructs}

Based on detailed literature review, metrics were identified for the components of the proposed model. The theory postulates brain drain is largely influenced by four factors namely socioeconomic, career development opportunities, importance of foreign branding and local market forces. Thus in our data set for this model, we have five constructs and 15 indicators, each construct having multiple indicators variables (Table 1).

Items were measured on a five point Likert scale with 'strongly agree'(1) and 'strongly disagree' (5).
Socioeconomic factor was measured with the help of three items. It can be safely assumed that higher levels of aspirations fuel a desire for higher standard of living. High salary is not always sufficient to satisfy personal needs, therefore people look to migrate to those parts of the world which can offer them and their family a more comfortable lifestyle which is stress free and disease free. The various items for which the response was measured are 'lack of moral values' (SE1), 'population pressure' (SE2) and 'high pollution levels' (SE3).

A high population puts enormous pressures both on the resources as well as on local talent. Therefore, a successful career development would mean securing a postgraduate university degree which can differentiate talent. Developed countries through sustained quality standards over the years have built themselves a reputation of offering world class education opportunities which is an attraction for deserving students. This was measured through variables namely 'higher career development prospects abroad (CE1), 'international experience paying dividends (CE2) and 'more higher education opportunities abroad' (CE3).

Foreign institutions offering quality and meritocracy will most certainly attract a strong goodwill across the globe. This factor influences decision making among prospective students who wish to take advantage of any association with an institution of global repute and return back to their native country. The various incentives for doing so could be measured as variables namely 'improved status in society back home' (FB1), and 'securing important institutional positions on return' (FB2).

As emerging economies see a rise in per capita incomes, students aspire to fulfil their dreams where they get maximum dividends for their time, efforts and inputs. Therefore, market forces as a factor determine the trend in terms of the flow of professionals and students. This was measured through various items, 'mismatched demand supply abroad' (MF1). 'Higher job satisfaction abroad' (MF2), 'domestic

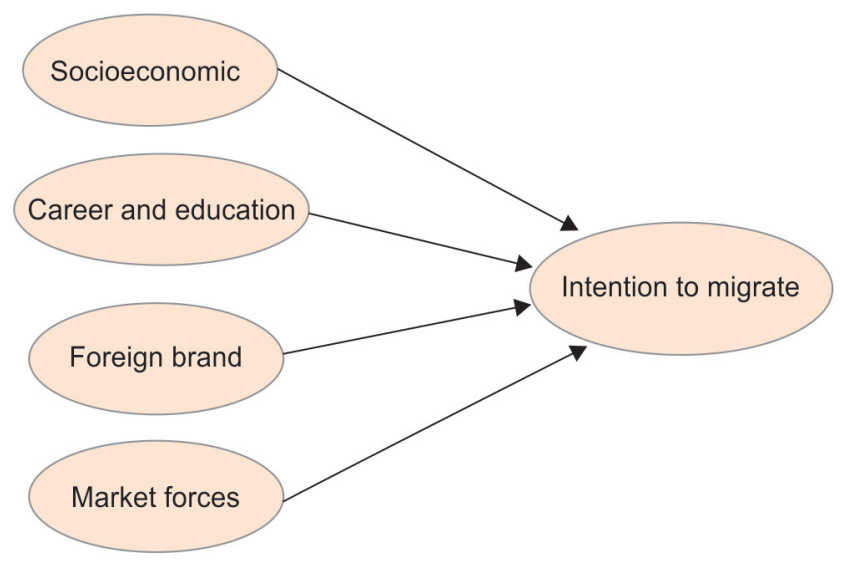

Fig. 1: Effect of various factors on intention to migrate 


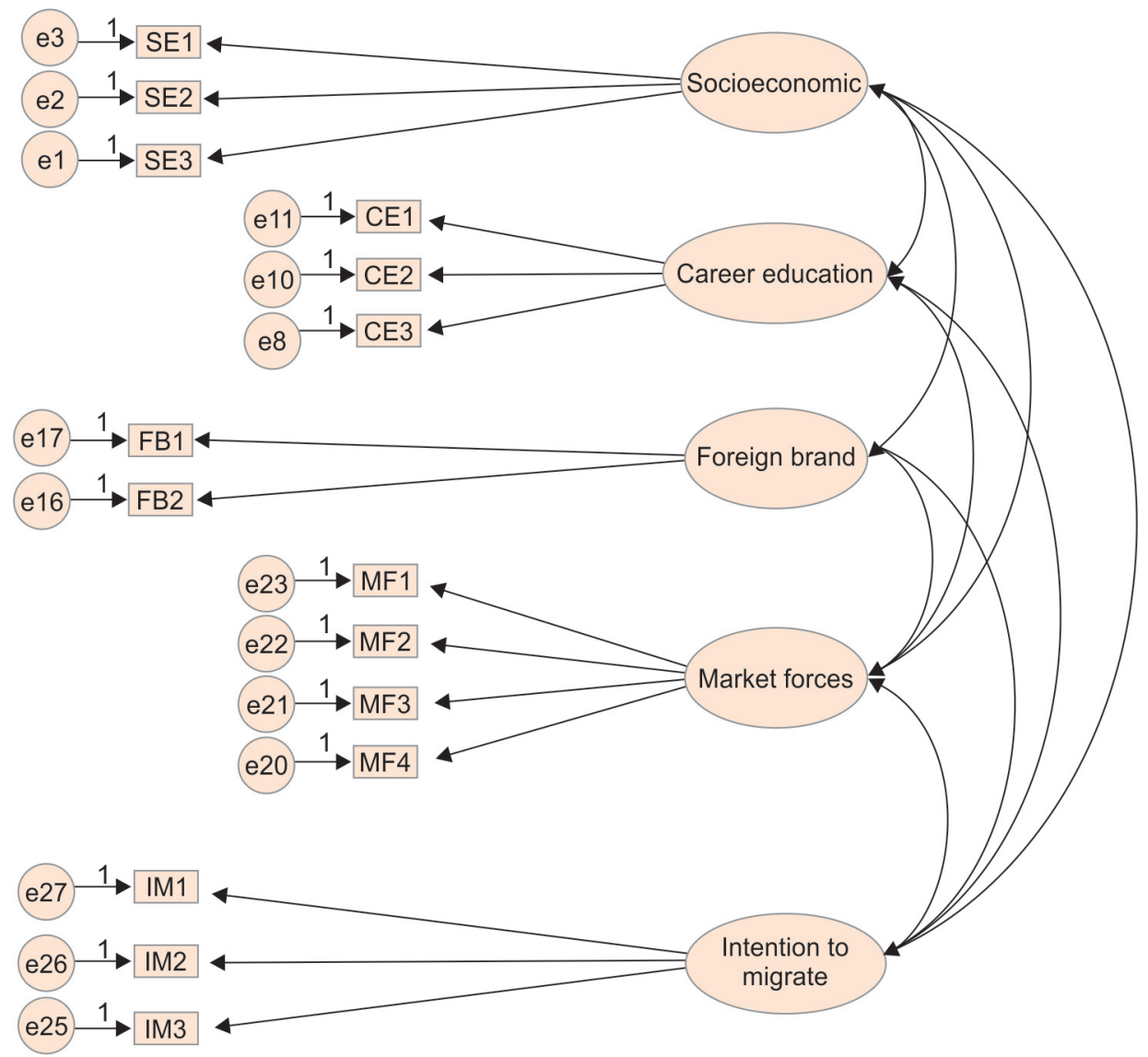

Fig. 2: Measurement model

Table 1: Definition of constructs

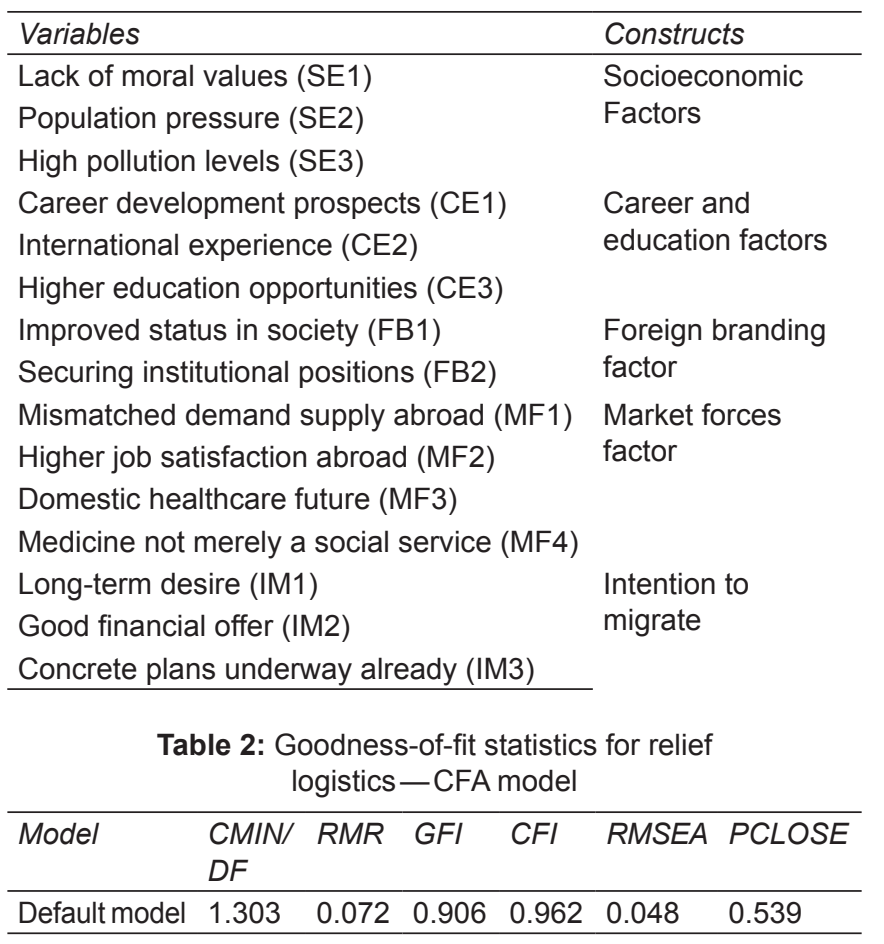

healthcare future not encouraging' (MF3). 'Medicine not merely seen as social service' (MF4).

All the above listed factors are considered in the final decision making process. The intention to migrate was measured through three variables namely 'long-term desire' (IM1), 'good financial offer' (IM2). and 'concrete plans underway already’ (IM3).

\section{Measurement Model}

Validity of measurement model was tested on the basis of psychometric properties of measures. In the proposed model, the reliability and validity of five constructs were tested. To test the measurement model, all construct were allowed to freely correlate with each and the factor loading of one observed variable per construct was fixed to a value of unity. All measured variable were allowed to load on only one construct (Unidimesional) and the error terms were not allowed to correlate with each other. The measurement model is described in Figure 2.

The relevant model statistics are shown in Table 2. The Chi-square minimum/degree of freedom (CMIN/DF) value of 1.303 reported by our model indicates that model fits the sample data reasonably well. The root mean residual (RMR) value of model has been observed to be 0.072 . Goodness of fit index (GFI) value of 0.906 and CFI value of 0.962 indicates good fit of model. Root mean square error of approximation (RMSEA) value equals 0.048 with PCLOSE value of 0.539 ( $>0.5$ ) further confirms fitness of model. 


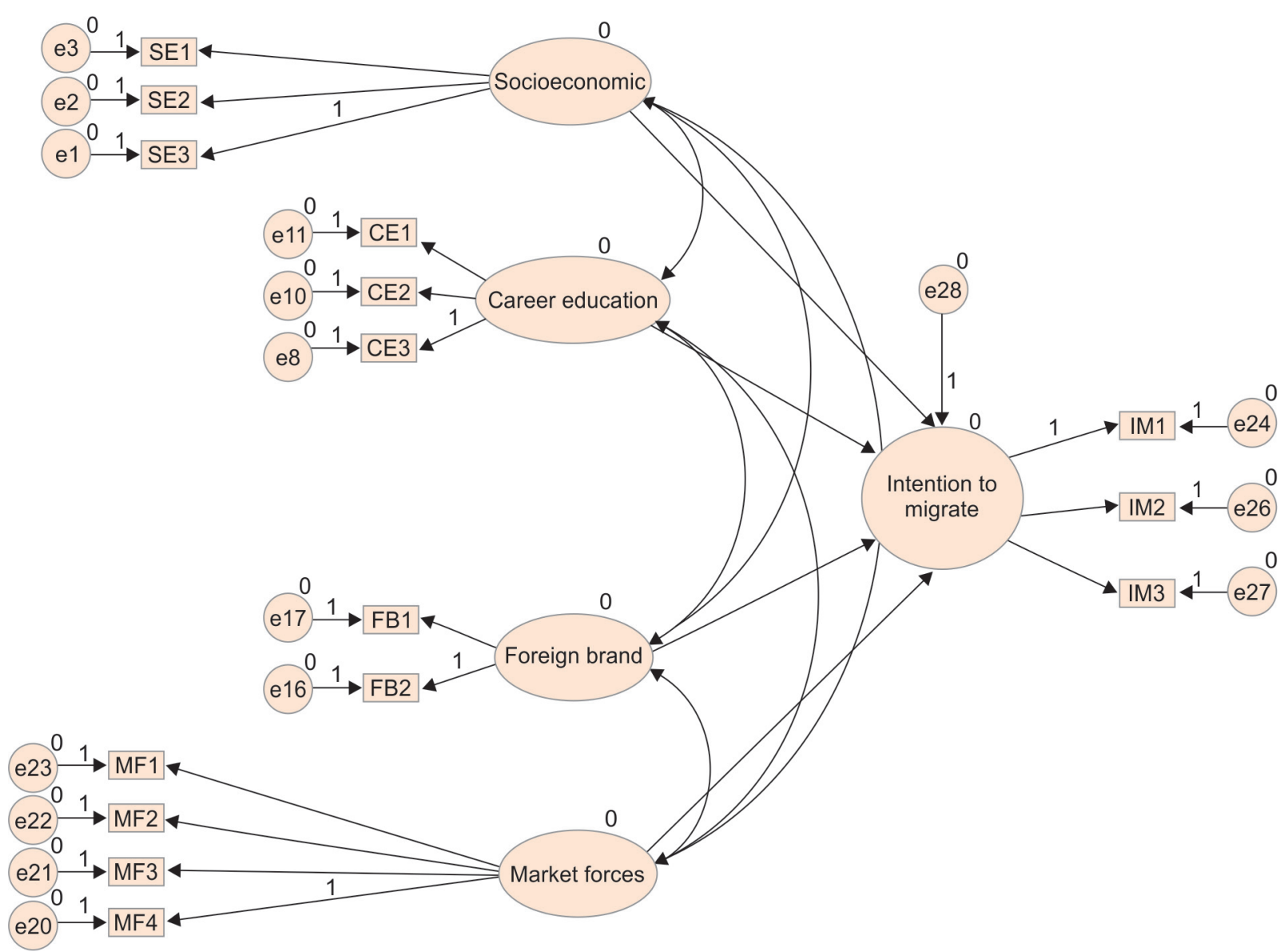

Fig. 3: Structural model

Table 3: Parameter estimates for the model

\begin{tabular}{|c|c|c|c|c|c|}
\hline Path & $\begin{array}{l}\text { Unstandardized } \\
\text { regression weights }\end{array}$ & $\begin{array}{l}\text { Standardized } \\
\text { regression weights }\end{array}$ & SE & $C R$ & $p$ \\
\hline Intention to migrate $\leftarrow$ Socioeconomic factors & 0.574 & 0.534 & 0.089 & 2.449 & $* \star *$ \\
\hline Intention to migrate $\leftarrow$ Career and education factors & 0.378 & 0.273 & 0.203 & 2.809 & *** \\
\hline Intention to migrate $\leftarrow$ Foreign brand factor & 0.338 & 0.296 & 0.085 & -0.517 & $* * *$ \\
\hline Intention to migrate $\leftarrow$ Market forces factor & 0.281 & 0.252 & 0.162 & 1.631 & *** \\
\hline
\end{tabular}

***Indicate significance, $p<0.001$ meaning $p$-value is smaller than (0.001), SE: Standard error, CR: Critical ratio

\section{Structural Model, the Effect of Various Factors on the Intent to Migrate}

The hypothesized model linking socioeconomic factor, career and education, foreign branding factor and market forces factor is shown in Figure 3. The model was tested using responses collected through sample survey.

The model was tested using responses collected through sample survey. The parameter estimated results, i.e. value of regression weights, standard errors, critical ratios of the model are presented in Table 3.

Standard errors are presented in Table 3. The values are ranging from 0.085 to 0.203 indicate that they are in good order. Further values of critical ratio were found to be significant at 0.001 level.

$\mathrm{H}_{1}$ stated improving the domestic socioeconomic conditions balances brain drain. As indicated in Table 3, the effect of socioeconomic factors is in hypothesized direction and it was statistically significant (std $\_\beta=0.534, \mathrm{p} \leq$ 0.001 ), therefore $H_{1}$ was supported. In $H_{2}$, it was stated that enhancing educational infrastructure positively influences professional migration. As indicated in Table 3 the effect of improved education and career opportunities is in hypothesized direction and it was statistically significant (std_ $\beta$ $=0.273, \mathrm{p} \leq 0.001$ ), thus we accept $\mathrm{H}_{2} . \mathrm{H}_{3}$ predicted that collaborating with foreign universities improves educational experience. As indicated in Table 3, the effect of foreign brand is in hypothesized direction and it was statistically significant (std $\_\beta=0.296, p \leq 0.001$ ), accordingly $\mathrm{H}_{3}$. In $\mathrm{H}_{4}$ it was predicted that bringing parity between healthcare and other industry sectors positively influences brain drain. As indicated in Table 3, the effect of market forces factor is in hypothesized direction and it was statistically significant 
Table 4: Goodness-of-fit statistics for the model

\begin{tabular}{lllllll}
\hline Model & $\begin{array}{l}\text { CMIN/ } \\
\text { DF }\end{array}$ & RMR & GFI & CFI & RMSEA & PCLOSE \\
\hline $\begin{array}{l}\text { Default } \\
\text { model }\end{array}$ & 1.303 & 0.072 & 0.906 & 0.962 & 0.048 & 0.539 \\
\hline
\end{tabular}

(std_ $\beta=0.252, p \leq 0.001$ ), thus we accept $\mathrm{H}_{4}$. Findings of goodness-of-fit statistics are presented in Table 4.

\section{CONCLUSION}

Healthcare migration offers us a tremendous opportunity for further research. Better understanding is needed in terms of the scale and nature of skill shortages in wealthy countries. The study presented in this paper identified and explained the role of various factors that influence skilled personnel in their decision to migrate to developed economies in search of more fruitful professionals opportunities.

The socioeconomic conditions of a particular country do impact the exodus of its personnel. Due to excessive wage differentials between rich and poor countries, small increments in wages would have little consequences in impacting supply of healthcare professionals. Aspiring youngsters do wish to settle in a country which provides them adequate law and order for their safety. It is observed that high levels of environmental pollution and population density have adverse effects on the decision to migration.

Present study highlighted the importance of career development in the decision to migrate. Mobility of skilled and health professionals is a reality in this day and age and the competition among countries for acquiring talent is only growing each day. It is wiser to accept and work positively to deal with this reality.

It cannot be stressed enough that there is a high demand for both quality and quantity as far as educational institutes are concerned. Therefore, lack of job and education opportunities leads to foreign migration among people. Increasing the number of education institutions to feed the growing demand is certainly needed. Also local industries need to be engaged in order to match skill development to the job requirements. For this to be achieved the teaching curriculum needs to be periodically revised to cater to the industry needs and requirements.

Demographic profile in most developed countries has created an enormous demand for skilled personnel. A shortage of skilled human resources, created due to a mismatch in demand-supply dynamics attracts human capital from developing countries. Educated migrants are rewarded suitably for their efforts, time and skills fuelling a desire within to fulfil their aspirations.

Remuneration parity between healthcare professionals with professionals in other sectors in the economy is crucial. India is an emerging economy which is driving prices higher each fiscal due to mismatched demand supply of resources. Also healthcare is one sector which is seen as a social service rather than any business opportunity. Compounding this problem is the fact professional's in IT, services and manufacturing blue collar jobs tread the path to carrier advancement much faster than healthcare personnel. Therefore, medical and paramedical personnel search for greener pastures abroad due to an ever increasing demand for healthcare in the higher income countries as a result of demographic realities and trends. Branding per se is a reflection of reliability and indicates good quality. Foreign universities and institutions of global repute offering opportunities to study and work are a great source of motivation and attraction among individuals.

Any international experience involving working with different people in diverse culture improves the technical know-how bringing with it crucial benefits as well. Doctors working overseas must search for ways and means to share their knowledge, expertise and resources.

Measures which can assist in attracting and reintegrating skilled professionals settled abroad could involve:

- Improving the academic and research system by initiating education and research reforms. Involving professionals who have demonstrated success measured through international accepted criteria.

- Creating a system of meritocracy in the country.

- Creating systems of excellence within a nation including elite institutes which have world class human financial and technical resources.

- Stimulating a culture of entrepreneurship within the country along with private research within an improved legal framework.

In the short-term authorities need to focus on stimulation and developing collaborations between professionals, doctors and skilled human resources with peers/institutions in their country of origin. This could be made possible by the following:

- Organizing international conferences, symposiums and workshops for doctors living abroad.

- Creating part time/visiting faculty jobs and positions for talent of international repute.

- Involving skilled human capital settled abroad to participate in projects in source countries for capitalizing on their knowledge and experience.

In the longer term approach, careful planning is needed to successfully integrate and reintegrate diasporas. The national education and research should see better integration with the international circuit. This approach needs both financial and cultural dimension with adequate focus on resource deployment. Highly skilled workforce gets attracted to world class centers of excellence. Therefore, 
encouraging quality research along with improved atmosphere for innovation and entrepreneurship has a positive impact on talent retention and attraction.

Internationally, developing countries need to work in unanimity since they are the affected the most. The General Agreement on Trade in Services (GATS), is an international framework, a treaty of the World Trade Organization (WTO). It was created to allow and fecilitate multilateral trading in the services sector. This will in turn promote free flow of service workers between countries. The collateral damage for countries, such as India would be possible increase in the rate of brain drain due to liberalized exchange in human workforce. GATS, could make human resource planning in source countries extremely difficult to manage since this treaty encourages free flow of personnel. Here, only with team work can the developing countries help themselves. It is important to make healthcare an exception to this treaty to protect the interest of millions in the developing world.

The present study has been restricted to India. Further, here responses have been gathered from the medical and dental sciences background. Therefore, the present study needs to be examined from contextual perspective.

There is an urgent need for better understanding of both the inward and outward flow of professional's through accurate and reliable data. This process would go a long way in understanding the consequences of such movement. Present study was confined to India only. Each country may have some specific metrics which affects them more. In this study, broadly four factors have been discussed which impact the decision to migrate. For a much broader perspective, few thought provoking questions can be considered for further study and a more detailed understanding on this subject.

First, what are the factors influencing migration of unskilled labor? Does the migration of skilled personnel have any relation with the demand for unskilled labor in the receiving country?

Second, if brain drain adversely impacts source country in its development, then limiting this phenomenon should be productive in nature. Do any kind of policy decisions on curbing brain drain have desirable long-term effects?

Third, this study is limited in its scope with respect to medical and dental streams. Are the factors discussed in this study equally applicable to other industry sectors namely Information Technology?

Finally, India although a developing country, has a large English speaking population. Do the above discussed factors hold true equally for non-English speaking country migrants? Do they have some other motivation and reasons for leaving their country?

\section{BIBLIOGRAPHY}

1. Adkoli BV. Migration of health workers: perspectives from Bangladesh, India, Nepal, Pakistan and Sri Lanka. In Regional Health Forum 2006;10(1):49-58.

2. Agrawal A, Kapur D, McHale J, Oettl A. Brain drain or brain bank? The impact of skilled emigration on poor-country innovation. J Urban Econom 2011;69(1):43-55.

3. Ahmad OB. Managing medical migration from poor countries. BMJ: 2005;331(7507):43.

4. Aiken LH, Buchan J, Sochalski J, Nichols B, Powell M. Trends in international nurse migration. Health Affairs 2004;23(3):69-77.

5. Beine M, Docquier F, Rapoport H. Brain drain and economic growth: theory and evidence. J Develop Economics, 2001;64(1): 275-289.

6. Beine M, Docquier F, Rapoport H. Brain drain and human capital formation in developing countries: winners and losers. Econo-mics J 2008;118(528):631-652.

7. Bhagwati J, Hamada K. The brain drain, international integration of markets for professionals and unemployment: a theoretical analysis. J Develop Economics 1974;1(1):19-42.

8. Bushnell P, Choy WK. Go West, Young Man, Go West!? (No. 01/07). New Zealand Treasury 2001.

9. Chen L, Evans T, Anand S, Boufford JI, Brown H, Chowdhury M, Wibulpolprasert S. Human resources for health: overcoming the crisis. Lancet 2004;364(9449):1984-1990.

10. Commander S, Kangasniemi M, Winters LA. The brain drain: curse or boon? A survey of the literature. In Challenges to Globalization: Analyzing the Economics. University of Chicago Press; 2004. p. 235-278.

11. De Haas H. International migration, remittances and development: myths and facts. Third World Quarterly, 2005;26(8): 1269-1284.

12. Desai MA, Kapur D, McHale J, Rogers K. The fiscal impact of high-skilled emigration: Flows of Indians to the US. J Develop Economics 2009;88(1):32-44.

13. Docquier F, Rapoport H. Skilled migration: the perspective of developing countries (No. 2873). IZA Discussion Papers 2007.

14. Docquier F, Rapoport H. Globalization, brain drain, and development. J Economics Liter 2012;50(3):681-730.

15. Docquier F, Rapoport H. The economics of the brain drain. J Econo Liter, Forthcoming 2011.

16. Easterly W, Levine R. What have we learned from a decade of empirical research on growth? It is Not Factor Accumulation: Stylized Facts and Growth Models. The World Bank Economic Review 2001;15(2):177-219.

17. Giannoccolo P. The brain drain: a survey of the literature. Università degli Studi di Milano-Bicocca, Department of Statistics, Working Paper, (2006-03), 2009;02.

18. Grubel HG, Scott A. The brain drain: determinants, measurement and welfare effects. Wilfrid Laurier Univ. Press 1977.

19. Guellec D, Cervantes M. International mobility of highly skilled workers: from statistical analysis to policy formulation. In International Mobility of Highly Skilled Workers 2002;71-98.

20. Hamada K, Bhagwati J. Domestic distortions, imperfect information and the brain drain. J Develop Economics 1975;2(3):265-279.

21. Hamilton K, Yau J. The global tug-of-war for health care workers. Migration Information Source 2004.

22. Henderson LN, Tulloch J. Incentives for retaining and motivating health workers in Pacific and Asian countries. Human Resources for Health 2008;6(1):18.

23. Hongoro C, McPake B. How to bridge the gap in human resources for health. Lancet 2004;364(9443):1451-1456. 
24. Available at: http://www.oecdobserver.org/news/archivestory. php/aid/673/The_brain_drain:Old_myths,_new_realities.html

25. Kangasniemi M, Winters LA, Commander S. Is the medical brain drain beneficial? Evidence from overseas doctors in the UK. Social Science \& Medicine 2007;65(5):915-923.

26. Kapur D, McHale J. Are We Losing the Global Race for Talent?. Wall Street J A17;2005.

27. Kapur D, McHale J. Give us your best and brightest: the global hunt for talent and its impact on the developing world 2005.

28. Kapur D, McHale J. The global migration of talent: what does it mean for developing countries? 2005.

29. Mountford A. Can a brain drain be good for growth in the source economy?. J Develop Economics 1997;53(2):287-303.

30. Mullan F. The metrics of the physician brain drain. New England J Med 2005;353(17):1810-1818.

31. Observer OECD. The brain drain: old myths, new realities 2002.

32. Popescu D, Patrasca M, Chivu I. Tendencies of international career of romanian researchers: brain drain? J App Quantit Meth 2006;1(2):194-209.
33. Rao M, Rao KD, Kumar AK, Chatterjee M, Sundararaman T. Human resources for health in India. Lancet 2011;377(9765): 587-598.

34. Salt J. International movements of the highly skilled (No. 3). OECD Publishing 1997.

35. Smith RD, Chanda R, Tangcharoensathien V. Trade in healthrelated services. Lancet 2009;373(9663):593-601.

36. Stilwell B, Diallo K, Zurn P, Vujicic M, Adams O, Dal Poz M. Migration of healthcare workers from developing countries: strategic approaches to its management. Bulletin of the World Health Organization 2004;82(8):595-600.

37. United Nations. Population Division. International Migration Report 2002 (Vol. 220). United Nations Publications 2002.

38. Wickramasekara P. Policy responses to skilled migration: Retention, return and circulation 2003.

39. Willis-Shattuck M, Bidwell P, Thomas S, Wyness L, Blaauw D, Ditlopo P. Motivation and retention of health workers in developing countries: a systematic review. BMC Health Services Research 2008;8(1):247. 